\title{
Anurofauna em área de cerrado aberto no município de Borebi, estado de São Paulo, Sudeste do Brasil: uso do habitat, abundância e variação sazonal
}

\author{
Fábio Maffei ${ }^{1,2}$, Flávio Kulaif Ubaid ${ }^{1}$ \& Jorge Jim ${ }^{1}$ \\ ${ }^{1}$ Departamento de Zoologia, Laboratório de Herpetologia, Instituto de Biociências de Botucatu, \\ Programa de Pós-graduação em Zoologia, Universidade Estadual Paulista - UNESP, \\ Distrito de Rubião Júnior s/n, CEP 18618-000, Botucatu, SP, Brasil \\ ${ }^{2}$ Autor para correspondência: Fábio Maffei, e-mail: maffei@ibb.unesp.br
}

MAFFEI, F., UBAID, F.K. \& JIM, J. Anurans in an open cerrado area in the municipality of Borebi, São Paulo state, Southeastern Brazil: habitat use, abundance and seasonal variation. Biota Neotrop. 11(2): http:// www.biotaneotropica.org.br/v11n2/en/abstract?article+bn04011022011

\begin{abstract}
Cerrado biome is mischaracterized and less than three percent of its original areas are legally protected. The anuran fauna of this biome is not very rich when compared with others biomes, but there are a large number of endemic species. Here we present a list of anuran species recorded in a pond in an open cerrado area in the municipality of Borebi, middle-western region of the São Paulo state, Southeastern Brazil. For 24 months (2008 and 2009), we characterized the distribution of species on the studied pond and seasonal variation of species occurrence. We recorded 27 species from six families: Bufonidae (two species), Cycloramphidae (one species), Hylidae (13 species), Leiuperidae (four species), Leptodactylidae (five species), and Microhylidae (two species). Species richness and abundance were related to rainfall. Dendropsophus minutus vocalized through the year, while Rhinella ornata and Odontophrynus americanus were restricted to the dry and cold period (April - August). The other species had their period of higher activity during the warm and rainy months (September - March). The distribution of species within the pond was related to the type of vegetation and to the variation on water volume of the pond, principally during dry periods. Anurans richness and abundance at the pond can be a result of the absence of predatory fish, the different types of available microhabitats and the absence of other water bodies nearby. Keywords: amphibians, community, savanna, inventory, seasonality.
\end{abstract}

MAFFEI, F., UBAID, F.K. \& JIM, J. Anurofauna em área de cerrado aberto no município de Borebi, estado de São Paulo, Sudeste do Brasil: uso do habitat, abundância e variação sazonal. Biota Neotrop. 11(2): http:// www.biotaneotropica.org.br/v11n2/pt/abstract?article+bn04011022011

Resumo: O bioma Cerrado encontra-se descaracterizado e menos de três por cento de suas áreas originais está legalmente protegida. A anurofauna desse bioma não é muito rica quando comparado a outros biomas, porém há um grande número de espécies endêmicas. Aqui apresentamos uma lista de espécies de anuros registrados em uma lagoa em área de cerrado aberto do município de Borebi, região Centro-Oeste do estado de São Paulo, sudeste do Brasil. Durante 24 meses de estudo (2008 e 2009) caracterizamos a distribuição das espécies na lagoa estudada e descrevemos a variação sazonal das espécies. Foram registradas 27 espécies pertencentes a seis famílias: Bufonidae (duas espécies), Cycloramphidae (uma espécie), Hylidae (13 espécies), Leiuperidae (quatro espécies), Leptodactylidae (cinco espécies) e Microhylidae (duas espécies). A riqueza de espécies e abundância estiveram relacionadas com a precipitação. Dendropsophus minutus foi a espécie mais abundante e com registro de vocalização durante o ano inteiro. Rhinella ornata e Odontophrynus americanus foram restritas ao período seco e frio (abril a agosto). As outras espécies tiveram seu período de maior atividade nos meses chuvosos e quentes (setembro a março). A ocupação da lagoa variou com o tipo de vegetação e conforme a variação do seu volume de água, principalmente nos período de estiagem. A alta riqueza e abundância de anuros da lagoa pode ser resultado da ausência de peixes predadores, dos diversos tipos de microambientes do local e da ausência de outros corpos d'água próximos.

Palavras-chave: anfíbios, comunidade, savana, inventário, sazonalidade. 


\section{Introdução}

O bioma Cerrado está distribuído em grande parte da região central do Brasil, no extremo nordeste do Paraguai e no leste da Bolívia (Gottsberger \& Silberbauer-Gottsberger 2006). É a segunda maior formação vegetal brasileira, ocupando um quarto do território nacional e superado em área apenas pela Amazônia (Ratter et al. 1997). Suas fisionomias variam desde formações abertas (campos ou savanas) até formações com aspecto florestal, tais como o cerradão e as matas de galeria (Eiten 1972). É considerado um dos 25 hotspots do planeta, que são áreas prioritárias para conservação caracterizadas pela grande concentração de espécies endêmicas, rica biodiversidade e ameaçada no mais alto grau (Myers et al. 2000). Mais da metade das áreas desse bioma já foram modificados pelo homem e apenas 2,2\% encontra-se em Unidades de Conservação (Klink \& Machado 2005). Segundo Machado et al. (2004), a taxa de desmatamento do Cerrado é alarmante, chegando a 1,5\% ao ano. Essas áreas vêm sendo substituídas por pastagens exóticas, culturas anuais e outros tipos de monoculturas (Klink \& Machado 2005). Estudos recentes estimam que o bioma fora das Unidades de Conservação deverá desaparecer no ano de 2030, caso o atual modelo de desenvolvimento seja mantido (Machado et al. 2004).

No estado de São Paulo, o Cerrado ocupava originalmente cerca de $14 \%$ do território, sendo que atualmente esta área representa menos de $1 \%$ da sua distribuição original, pulverizados em 8.300 fragmentos, e metade deles é menor que 10 ha (Kronka et al. 1998, 2005). Os cerrados paulistas possuem formações que vão desde áreas abertas (campo limpo, campo sujo, campo cerrado e cerrado típico) até áreas florestadas (cerradão). Contudo, as áreas de formação campestres ou savanas são poucas e vêm sendo fortemente degradadas (Durigan et al. 2004).

Atualmente, são conhecidas 141 espécies de anfíbios para o Cerrado, sendo que várias espécies vêm sendo descritas e ainda faltam amostragens adequadas em várias regiões (Colli et al. 2002, Bastos 2007). O número de espécies é considerado baixo em relação ao tamanho do bioma, o que pode ser atribuído principalmente ao baixo índice pluviométrico anual e à estação seca prolongada (Duellman 1999). Vasconcelos et al. (2010) relatam que a concentração das chuvas ao longo do ano é um importante fator regulador nas comunidades de anuros no Cerrado. Entretanto, o endemismo do grupo em relação a outros vertebrados é alto, com 47 espécies (33\%) restritas a esse bioma (Bastos 2007).

Das 231 espécies de anfíbios registradas para o estado de São Paulo, apenas 58 ocorrem em áreas de Cerrado (Araújo et al. 2009a). Segundo Haddad (1998), o Cerrado paulista apresenta uma anurofauna naturalmente mais empobrecida em relação às áreas de Mata Atlântica, pois os ambientes abertos desse ecossistema permitem poucas especializações reprodutivas aos anuros, restringindo o número de grupos filogenéticos que podem ocupar estas áreas. Os levantamentos de anuros no Cerrado paulista foram realizados em áreas de transição com Floresta Estacional Semidecidual (e.g., Jim 1980, 2003, Bernarde \& Kokubum 1999, Vasconcelos \& Rossa-Feres 2005, Araujo et al. 2009b), cerradão (e.g., Melo et al. 2007, Ribeiro Junior \& Bertoluci 2009) e cerrado aberto (Brasileiro et al. 2005). No presente trabalho, apresentamos uma lista de espécies de anuros em uma lagoa em área de cerrado aberto no município de Borebi (SP), caracterizamos a distribuição das espécies na lagoa estudada e descrevemos a variação sazonal das espécies registradas.

\section{Material e Métodos}

\section{1. Área de estudo}

O estudo foi realizado na Fazenda Rio Pardo, localizada no sul do município de Borebi ( $22^{\circ} 48^{\prime}$ S e $49^{\circ} 00^{\prime \prime}$ O), região Centro-Oeste do estado de São Paulo (Figura 1), sudeste do Brasil. A fazenda possui plantios de Eucalyptus saligna e fragmentos de cerrado "stricto sensu". A altitude do local é de $650 \mathrm{~m}$ e o relevo é plano. De acordo com a classificação de Köppen, o clima da região é do tipo Cwa (tropical de altitude), que abrange toda a parte central do estado de São Paulo e é caracterizado por chuvas no verão e seca no inverno. A temperatura média mensal mínima registrada durante o trabalho foi de $8,8^{\circ} \mathrm{C}$ (maio de 2008 e junho de 2009) e a média mensal máxima foi de $29,8{ }^{\circ} \mathrm{C}$ (janeiro de 2009). A precipitação anual total foi de 1279,4 mm em 2008 e 1944,9 mm em 2009.

A área está inserida na região hidrográfica do médio Paranapanema, com seus cursos d'água drenando para o rio Pardo, que por sua vez deságua no rio Paranapanema. Predomina o latossolo vermelhoamarelo, fase arenosa, que propicia a ocorrência de vegetação de campos na maior parte da região (Carpanezzi et al. 1975). No entorno da fazenda são desenvolvidas atividades agrícolas, predominando o cultivo da laranja, cana-de-açúcar, pastagens e plantações de eucalipto.

O local de amostragem foi uma lagoa localizada no centro da fazenda (Figura 2). No período chuvoso, o nível da água é controlado por um dique, que limita o escoamento da água. O espelho d'água tem aproximadamente $150 \mathrm{~m}$ de largura e $250 \mathrm{~m}$ de extensão. Nos meses mais secos (abril a agosto), o volume de água é reduzido pela metade. Há predominância de vegetação emergente nas margens da lagoa, que é gradualmente substituída por vegetação herbáceoarbustiva (gramíneas, touceiras e pequenos arbustos) e arbustos espaçados, conforme se distancia da lagoa (Figura 3). No final da lagoa forma-se um encharcado com um taboal no centro. Em algumas regiões marginais da lagoa a vegetação é predominantemente arbórea, porém sem formação de dossel. No período chuvoso, a água da lagoa transborda próximo ao dique formando um alagado com aspecto de poça temporária com aproximadamente $2 \times 5 \mathrm{~m}$. São ambientes exclusivamente abertos com insolação total.

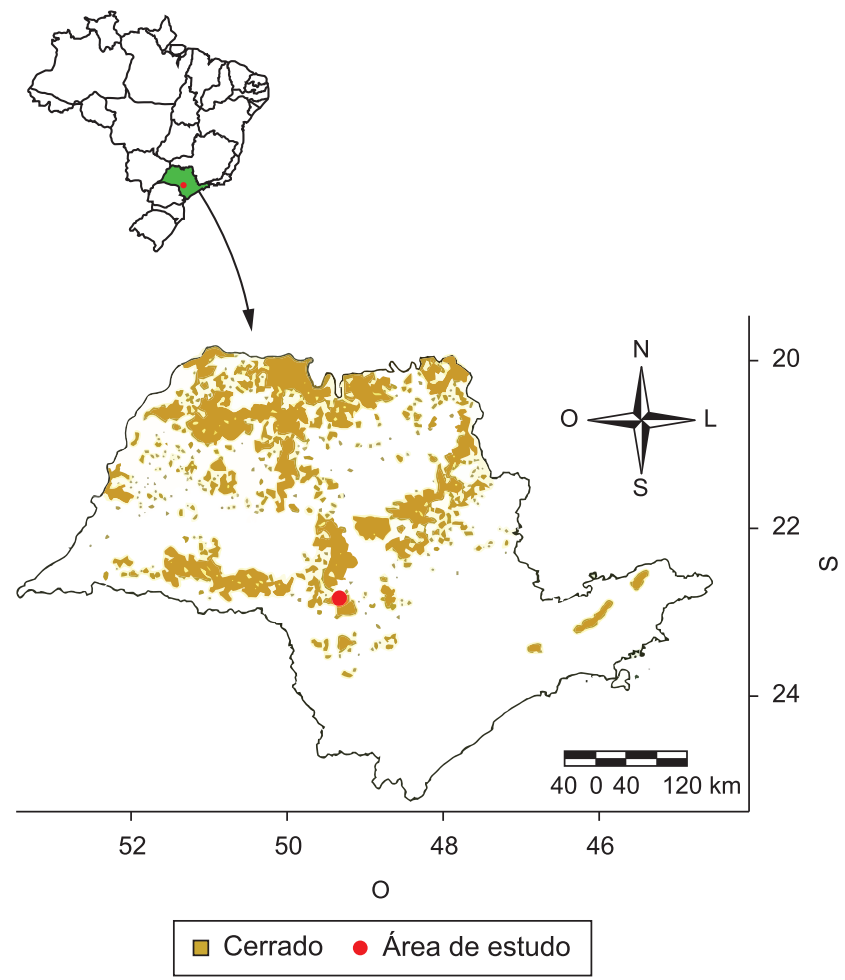

Figura 1. Localização geográfica da área de estudo no estado de São Paulo. [Fonte: modificado de CRIA (Centro... 2009)].

Figure 1. Geographical location of the study area in the São Paulo state. [Source: modified of (Centro... 2009)]. 


\section{Coleta e análise dos dados}

Os dados foram coletados de janeiro de 2008 a dezembro de 2009 com visitas mensais, totalizando 24 noites de coleta. Para o registro das espécies foram utilizados os métodos de levantamento por encontro visual (Crump \& Scott Junior 1994) e procura auditiva (Zimmerman 1994). A cada visita, a abundância de cada espécie foi estimada pelo número de machos vocalizando. A borda da lagoa foi percorrida lentamente, partindo de um ponto inicial diferente a cada visita. O percurso não foi linear, já que os indivíduos podiam estar vocalizando na área central ou externamente às margens da lagoa (Rossa-Feres \& Jim 2001).

Espécimes-testemunho foram coletados manualmente e acondicionados em sacos plásticos umedecidos. Posteriormente, foram anestesiados e mortos com xilocaína em pasta a $5 \%$, e em seguida fixados em formalina a $10 \%$. Após cinco dias, foram conservados em
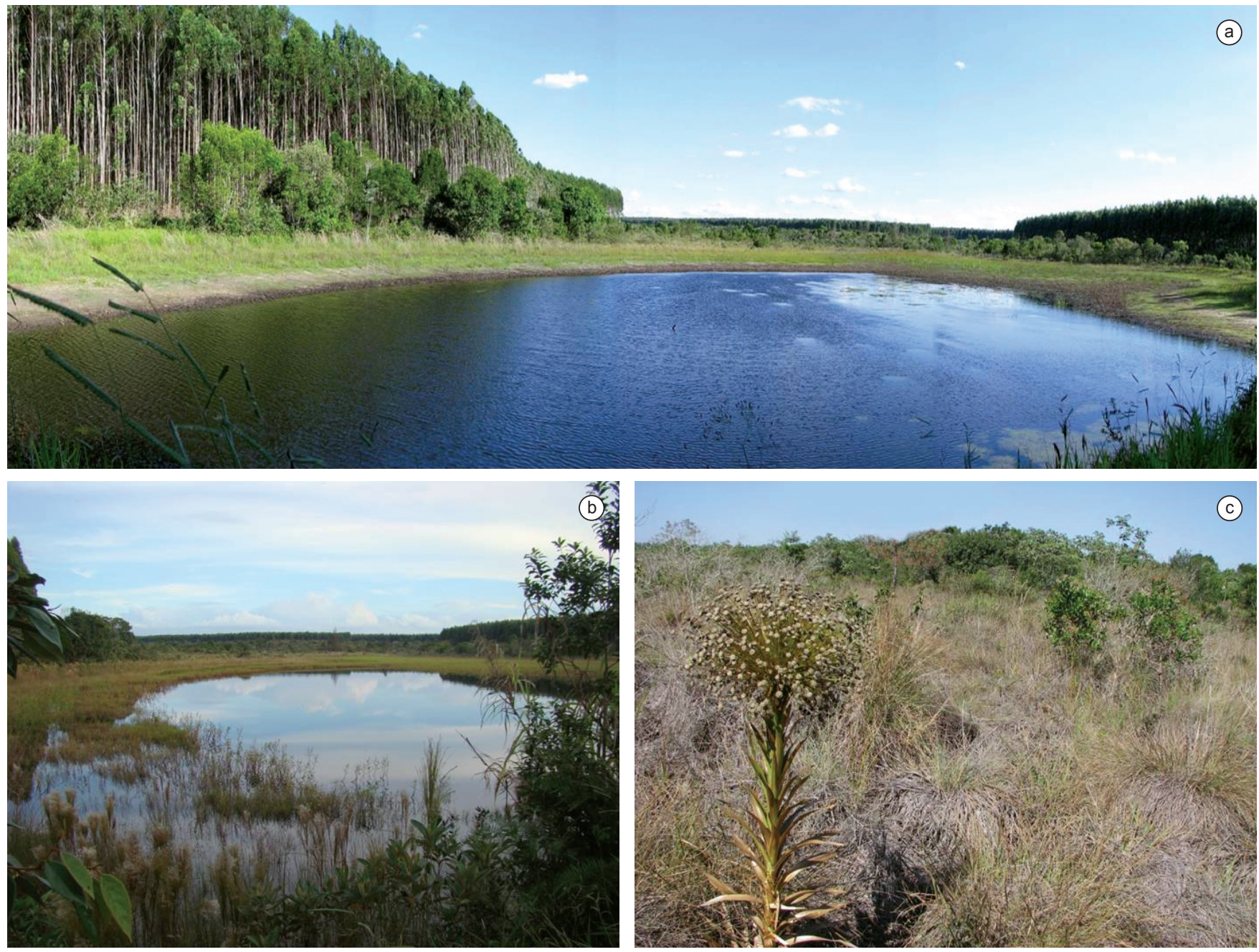

Figura 2. Lagoa amostrada na Fazenda Rio Pardo, município de Borebi: a) Visão geral da lagoa em período seco; b) Visão geral da lagoa em período chuvoso; c) Vegetação de Cerrado ao redor da lagoa.

Figure 2. Pond sampled in the Rio Pardo Farm, municipality of Borebi: a) General view of the pond in the dry season; b) General view of the pond in the rainy season; c) Cerrado vegetation around the pond.

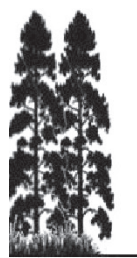

12

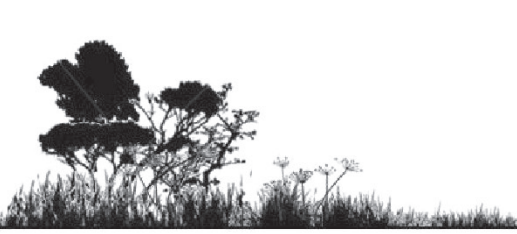

3

4

5

6

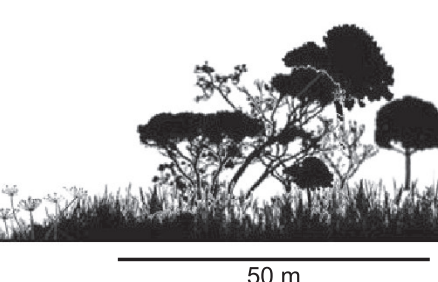

Figura 3. Diagrama do perfil da vegetação da lagoa estudada: 1) eucalipto, 2) estrada, 3) vegetação arbórea-arbustiva, 4) vegetação herbácea, 5) vegetação emergente, 6) lâmina d'água.

Figure 3. Vegetation profile diagram of the studied pond: 1) eucalyptus, 2) road, 3) arboreal-shrubby vegetation, 4) herbaceous vegetation, 5) emergent vegetation, 6) water surface. 
álcool $70 \%$ e tombados na Coleção Científica Jorge Jim, localizada no Laboratório de Herpetologia do Departamento de Zoologia do Instituto de Biociências de Botucatu da Universidade Estadual Paulista "Júlio de Mesquita Filho" (Apêndice 1). A nomenclatura das espécies adotada no trabalho segue Frost (2010).

A frequência de ocorrência das espécies foi analisada pelo índice de constância de ocorrência (Dajoz 1972) expresso em porcentagem, sendo que as espécies foram categorizadas em: comuns $(\mathrm{C}>50 \%$ - registradas em mais de 12 visitas); relativamente comuns ( $25 \% \leq \mathrm{C} \leq 50 \%$ registradas entre seis e 12 vistas); e ocasionais $(\mathrm{C}<25 \%$ - registradas em menos de cinco visitas). A abundância relativa foi analisada através da porcentagem do número de registros de cada espécie em relação ao número de registros total (Magurran 1988).

A eficiência da amostragem foi avaliada pela curva de acumulação de espécies construída com dados de presença e ausência das espécies em cada mês, num total de 24 amostras. Os cálculos foram realizados com base em 1000 aleatorizações utilizando o estimador não-paramétrico Bootstrap com o uso do programa EstimateS 7.5 (Smith \& van Belle 1984, Colwell 2005). Esse estimador foi escolhido por considerar dados de todas as espécies registradas, diferentemente dos demais estimadores não-paramétricos que se baseiam em espécies raras (Santos 2003).

Para testar a relação entre as variáveis climáticas (precipitação total mensal e temperatura média mínima dos cinco dias anteriores ao dia da coleta) e a riqueza e abundância da comunidade estudada, foi utilizado o coeficiente de correlação de Spearman $\left(r_{S}\right)$. As correlações foram realizadas independentemente considerando cada variável climática com riqueza e abundância. $O$ índice $r_{S}$ foi escolhido devido à não-normalidade da distribuição dos dados. Devido a correlação existente entre a média das temperaturas máximas e mínimas, foram excluídas das análises os dados de temperatura média máxima por apresentarem menor coeficiente de variação $(\mathrm{CV}=12,58 \%)$. Foi utilizado o programa BioEstat 5.0 (Ayres et al. 2007), e o nível de significância adotado para as análises foi $\mathrm{p}<0,05$. Os dados ambientais utilizados nas análises foram obtidos a partir de uma estação meteorológica de uma fazenda vizinha distante cerca de $10 \mathrm{~km}$ da área de estudo.

\section{Resultados}

Foram registradas 27 espécies de anfíbios anuros pertencentes a 11 gêneros distribuídos em seis famílias (Tabela 1, Figura 4). A família Hylidae correspondeu à metade das espécies registradas $(\mathrm{n}=13)$. O restante foi representado pelas famílias Leptodactylidae $(\mathrm{n}=5)$, Leiuperidae $(\mathrm{n}=4)$, Microhylidae $(\mathrm{n}=2)$, Bufonidae $(\mathrm{n}=2)$ e Cycloramphidae $(\mathrm{n}=1)$. Rhinella schneideri foi registrada após o período de estudo.

Apenas duas espécies (8\%) foram consideradas comuns (Dendropsophus minutus e Physalaemus cuvieri). As espécies relativamente comuns corresponderam a $46 \%(\mathrm{n}=12)$ e as ocasionais, também somaram $46 \%(\mathrm{n}=12)$. Espécies como Hypsiboas albopunctatus, Scinax fuscomarginatus e $S$. fuscovarius foram consideradas relativamente comuns, porém foram registradas em mais de dez visitas. Apenas Chiasmocleis albopunctata e Odontophrynus americanus foram registradas somente em uma visita. A abundância relativa de 18 espécies foi menor que 2\% (Figura 5). Dendropsophus minutus teve uma abundância relativa de 40,98\%, que somado aos registros de Scinax fuscovarius $(20,92 \%)$ corresponderam a quase $2 / 3$ de todos os registros. Leptodactylus latrans, a espécie menos abundante nas amostragens, foi registrado em três visitas, sempre com um indivíduo.

A curva cumulativa de espécies registradas atingiu sua assíntota a partir da $21^{\text {a }}$ visita (setembro de 2009). Entretanto, o estimador Bootstrap calculou 27,9 $( \pm 0,0)$ espécies para a área e a sua curva apresentou forte tendência à estabilização (Figura 6).
O período de vocalização das espécies registradas esteve associado em sua maioria ao período chuvoso - setembro a março. A riqueza de espécies esteve correlacionada com a temperatura média mínima $\left(\mathrm{r}_{\mathrm{s}}=0,67, \mathrm{p}<0,05\right)$ e com a precipitação $\left(\mathrm{r}_{\mathrm{S}}=0,69\right.$, $\mathrm{p}<0,05)$, sendo que a maior riqueza foi registrada em um dos picos de precipitação (janeiro de 2009). Do mesmo modo, a abundância esteve correlacionada com a temperatura média mínima $\left(\mathrm{r}_{\mathrm{S}}=0,50\right.$, $\mathrm{p}<0,05)$ e precipitação $\left(\mathrm{r}_{\mathrm{s}}=0,46, \mathrm{p}<0,05\right)$.

A variação da temperatura mínima foi mais evidente em relação à temperatura máxima. Nos meses mais frios (maio a julho) foram observadas as menores riquezas, com diminuição considerável da abundância, chegando a zero indivíduos em abril de 2008. Machos de Rhinella ornata e Odontophrynus americanus vocalizaram apenas no período seco. Os de Dendropsophus minutus vocalizaram o ano todo, mas com maiores abundâncias no período chuvoso. A maioria dos hilídeos vocalizou durante toda estação chuvosa (Figura 7). Os leiuperídeos apresentaram curtos períodos de vocalização sempre no auge das chuvas, exceto Physalaemus cuvieri, cujos machos vocalizaram durante toda a estação chuvosa. Nenhum leptodactilídeo foi registrado vocalizando fora do período chuvoso.

A vegetação emergente e marginal da lagoa foi utilizada principalmente pelos hilídeos de pequeno porte. Os hilídeos de maior porte (Hypsiboas faber e Phyllomedusa tetraploidea) vocalizaram distantes da água, associados ao substrato de maior porte. Machos de Dendropsophus anceps vocalizaram apenas no taboal e Scinax berthae e $S$. squalirostris vocalizaram na vegetação herbácea (touceiras de capim fino) ao lado do taboal. As maiores agregações de indivíduos se deram ao redor do taboal e da poça temporária. Machos de Leptodactylus mystacinus e L. mystaceus vocalizaram em áreas de solo seco, distante da lagoa, porém no auge das chuvas ambas as espécies tiveram suas maiores abundâncias na área encharcada próxima ao taboal.

Os leiuperídeos vocalizaram nas extremidades da lagoa, nunca nas margens laterais (Figura 8). No período de estiagem, a lagoa teve seu espelho d'água reduzido pela metade, sendo que no início do mês de dezembro de 2008 apenas uma pequena área na parte central desse ambiente acumulou água. Em outubro e novembro de 2008, toda a borda da lagoa ficou sem vegetação e com o solo exposto. Nesse período, mais de 100 indivíduos de Leptodactylus fuscus foram registrados vocalizando próximos de suas tocas. Nos meses de agosto e setembro de ambos os anos, Dendropsophus minutus e Scinax fuscovarius vocalizaram somente no solo.

\section{Discussão}

A composição da anurofauna registrada no presente estudo assemelha-se a outras comunidades de anuros amostradas no Cerrado (Brasileiro et al. 2005, Vitt et al. 2005), com maior representatividade das famílias Hylidae e Leptodactylidae. Foram registradas espécies típicas de Cerrado, como Dendropsophus jimi e D. elianeae (Napoli \& Caramaschi 1999, Brasileiro et al. 2005) e espécies características da Mata Atlântica, como Rhinella ornata e Dendropsophus anceps (Baldissera Junior et al. 2004, Rolim et al. 2008). Dendropsophus anceps foi registrada por Rolim et al. (2008) em diversos pontos a cerca de $5 \mathrm{~km}$ da lagoa estudada, sendo esta a segunda população conhecida para o estado de São Paulo.

Apenas duas espécies foram consideradas comuns e o restante foi dividido entre espécies relativamente comuns e ocasionais. Apesar desse padrão ser recorrente em comunidades de anuros (e.g., Melo et al. 2007, Moraes et al. 2007), a maioria dos estudos envolvendo o grupo são anuais impossibilitando a detecção de eventuais alterações na frequência de ocorrência das espécies. Analisando separadamente os dados obtidos em cada ano deste estudo, é possível observar diferenças na frequência de ocorrência: no primeiro ano, duas espécies $(8 \%)$ foram comuns, nove espécies relativamente comuns $(35 \%)$ e 15 ocasionais $58 \%(\mathrm{n}=15)$. Já 

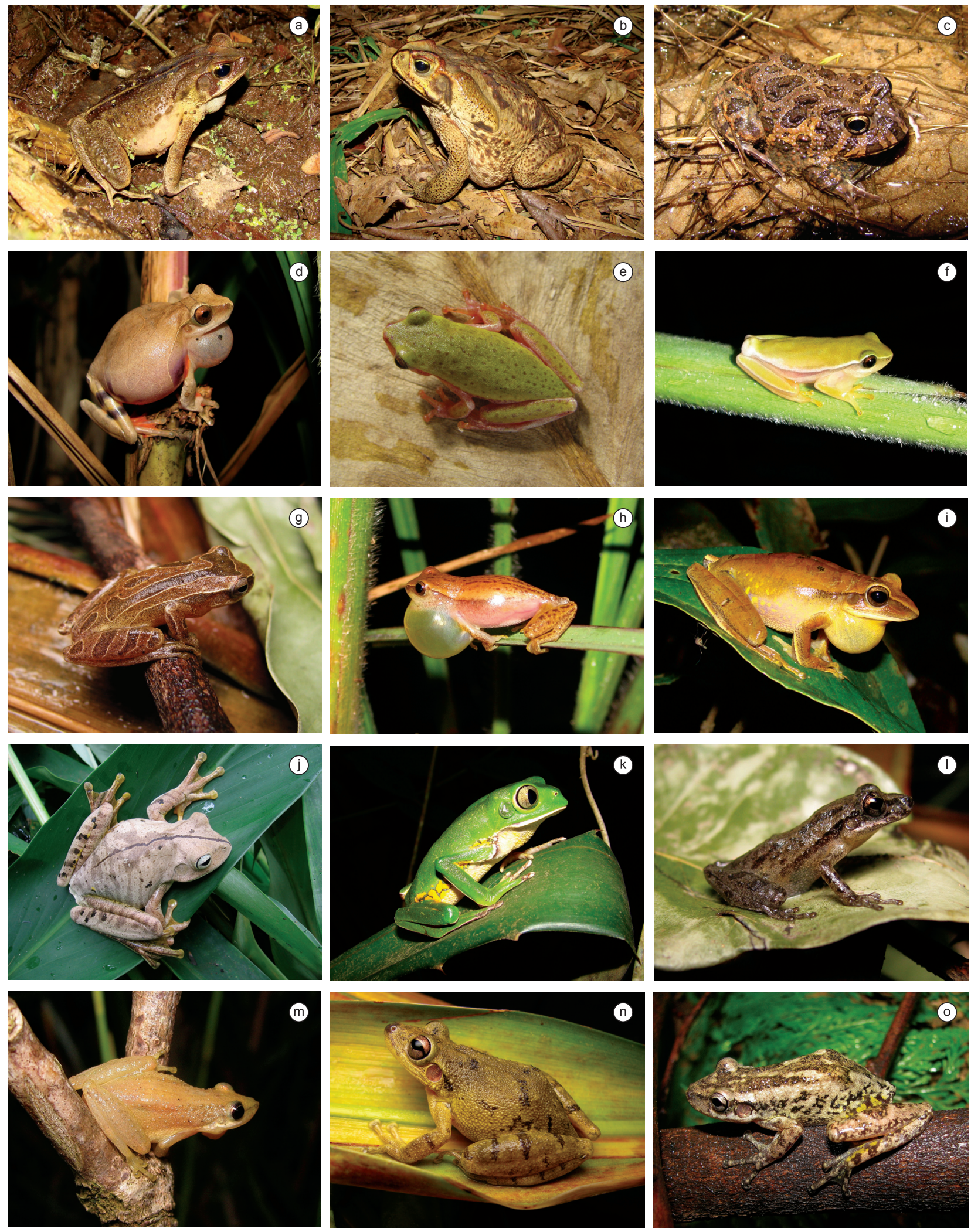

Figura 4. Espécies de anfíbios anuros registradas na Fazenda Rio Pardo, município de Borebi, estado de São Paulo, sudeste do Brasil, entre janeiro de 2008 e dezembro de 2009. a) Rhinella ornata; b) Rhinella schneideri; c) Odontophrynus americanus; d) Dendropsophus anceps; e) Dendropsophus elianeae; f) Dendropsophus jimi; g) Dendropsophus minutus; h) Dendropsophus nanus; i) Hypsiboas albopunctatus; j) Hypsiboas faber; k) Phyllomedusa tetraploidea; 1) Scinax berthae; m) Scinax fuscomarginatus; n) Scinax fuscovarius; o) Scinax similis.

Figure 4. Anurans recorded in the Rio Pardo Farm, municipality of Borebi, São Paulo state, Southeastern Brazil, between January 2008 and December 2009. a) Rhinella ornata; b) Rhinella schneideri; c) Odontophrynus americanus; d) Dendropsophus anceps; e) Dendropsophus elianeae; f) Dendropsophus jimi, g) Dendropsophus minutus; h) Dendropsophus nanus; i) Hypsiboas albopunctatus; j) Hypsiboas faber; k) Phyllomedusa tetraploidea; 1) Scinax berthae; m) Scinax fuscomarginatus; n) Scinax fuscovarius; o) Scinax similis. 

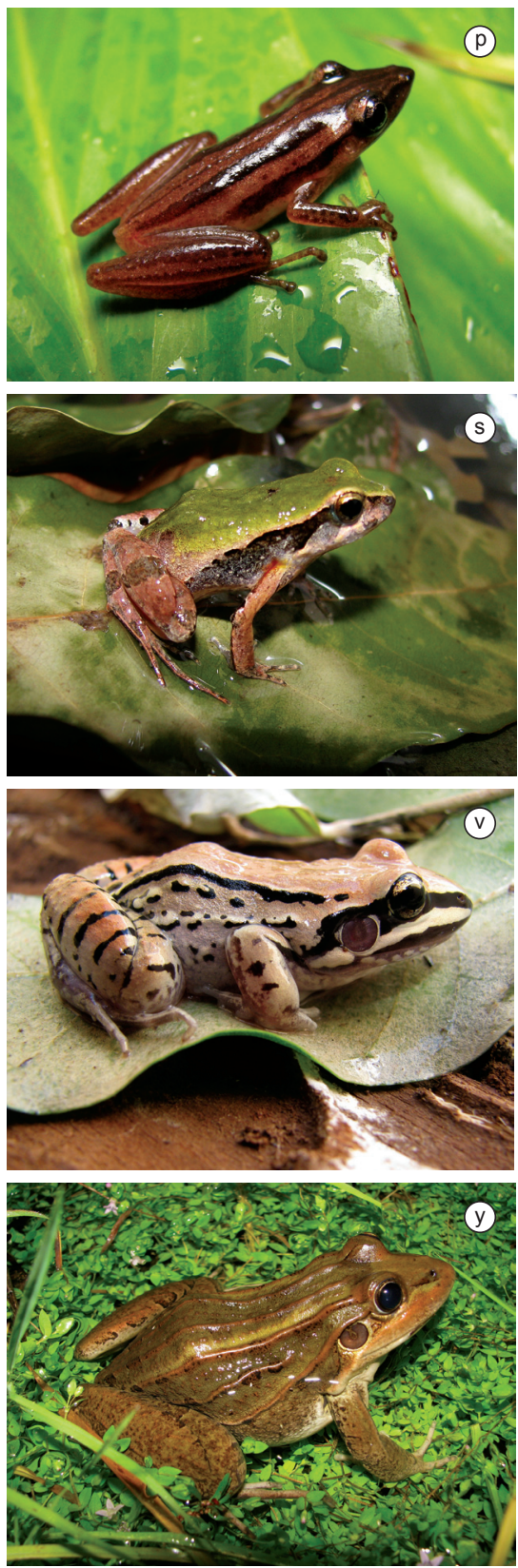
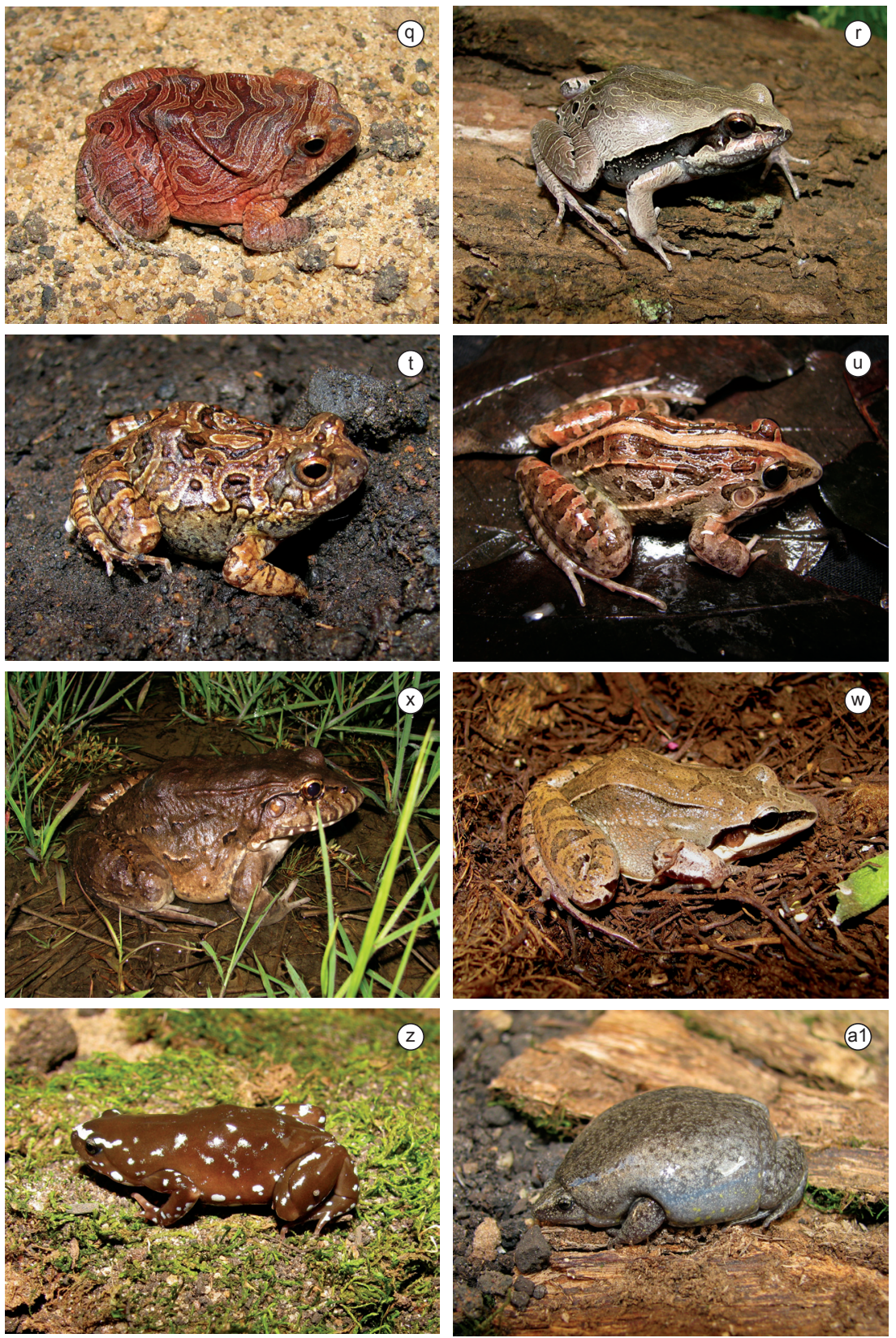

Figura 4. Espécies de anfíbios anuros registradas na Fazenda Rio Pardo, município de Borebi, estado de São Paulo, sudeste do Brasil, entre janeiro de 2008 e dezembro de 2009. p) Scinax squalirostris; q) Eupemphix nattereri; r) Physalaemus centralis; s) Physalaemus cuvieri; t) Physalaemus marmoratus; u) Leptodactylus fuscus; v) Leptodactylus mystacinus; x) Leptodactylus labyrinthicus; w) Leptodactylus mystaceus; y) Leptodactylus latrans; z) Chiasmocleis albopunctatus; a1) Elachistocleis ovalis.

Figure 4. Anurans recorded in the Rio Pardo Farm, municipality of Borebi, São Paulo state, Southeastern Brazil, between January 2008 and December 2009. p) Scinax squalirostris; q) Eupemphix nattereri; r) Physalaemus centralis; s) Physalaemus cuvieri; t) Physalaemus marmoratus; u) Leptodactylus fuscus; v) Leptodactylus mystacinus; x) Leptodactylus labyrinthicus; w) Leptodactylus mystaceus; y) Leptodactylus latrans; z) Chiasmocleis albopunctatus; a1) Elachistocleis ovalis.

no segundo ano, nenhuma espécie foi classificada como comum, cinco espécies foram relativamente comuns $(19 \%)$ e 21 espécies ocasionais (81\%). Na Figura 7 observa-se que as chuvas do segundo ano ocorreram de forma mais concentrada em relação ao primeiro, fato que pode estar relacionado às alterações nas frequências de ocorrência das espécies.

Dendropsophus minutus e Scinax fuscovarius foram dominantes em relação à comunidade, correspondendo juntas a 61,90\% de todos os registros. Essas duas espécies são comuns em comunidades do Cerrado ocorrendo normalmente em alta abundância (Brasileiro et al. 2005; Rodrigues et al. 2005; Melo et al. 2007).
O resultado do estimador Bootstrap mostrou que a comunidade foi bem amostrada, porém indica que algumas espécies ainda podem ser registradas na lagoa estudada. Outras espécies de área aberta muito comuns na região não foram registradas como, por exemplo, Hypsiboas caingua e Leptodactylus podicipinus (Jim 2003). Cerca de um ano após o término do estudo, em uma visita a lagoa estudada, dois indivíduos de Rhinella schneideri foram registrados transitando em sua margem.

A precipitação foi a variável que mais influenciou a variação sazonal das espécies de anuros registradas, sendo que os maiores valores de riqueza e abundância estiveram positivamente relacionados 
Tabela 1. Lista das espécies de anfíbios anuros registradas na Fazenda Rio Pardo, município de Borebi, estado de São Paulo, sudeste do Brasil, entre janeiro de 2008 e dezembro de 2009.

Table 1. Anuran species list recorded in the Rio Pardo Farm, municipality of Borebi, São Paulo state, Southeastern Brazil, between January 2008 and December 2009.

\begin{tabular}{|c|c|c|c|c|c|}
\hline Famílias e espécies & Siglas & $\operatorname{AR}(\%)$ & $\mathbf{A M}$ & $\mathrm{C}(\%)$ & Substrato \\
\hline \multicolumn{6}{|l|}{ Bufonidae } \\
\hline Rhinella ornata (Spix, 1824) & Rorn & 0,06 & 3 & 12,5 & $\mathrm{~S}$ \\
\hline Rhinella schneideri (Werner, 1894)* & Rsch & - & - & - & $\mathrm{S}$ \\
\hline \multicolumn{6}{|l|}{ Cycloramphidae } \\
\hline Odontophrynus americanus (Duméril \& Bibron, 1841) & Oame & 0,37 & 35 & 4,2 & $\mathrm{~S}$ \\
\hline \multicolumn{6}{|l|}{ Hylidae } \\
\hline Dendropsophus anceps (A. Lutz, 1929) & Danc & 0,57 & 30 & 16,7 & $\mathrm{~T}$ \\
\hline Dendropsophus elianeae (Napoli \& Caramaschi, 2000) & Deli & 1,17 & 50 & 25 & VE, $\mathrm{H}$ \\
\hline Dendropsophus jimi (Napoli \& Caramaschi, 1999) & Djim & 1,37 & 100 & 20,8 & VE, $\mathrm{H}$ \\
\hline Dendropsophus minutus (Peters, 1872) & Dmin & 40,96 & 895 & 95,8 & $\mathrm{~S}, \mathrm{~T}, \mathrm{VE}, \mathrm{H}$ \\
\hline Dendropsophus nanus (Boulenger, 1889) & Dnan & 2,58 & 200 & 29,2 & VE, $\mathrm{H}$ \\
\hline Hypsiboas albopunctatus (Spix, 1824) & Halb & 1,32 & 23 & 45,8 & $\mathrm{~T}, \mathrm{AB}$ \\
\hline Hypsiboas faber (Wied-Neuwied, 1821) & $H f a b$ & 0,09 & 2 & 29,2 & $\mathrm{H}$ \\
\hline Phyllomedusa tetraploidea Pombal Junior \& Haddad, 1992 & Ptet & 1,06 & 50 & 37,5 & $\mathrm{H}, \mathrm{AB}$ \\
\hline Scinax berthae (Barrio, 1962) & Sber & 0,39 & 20 & 13 & $\mathrm{H}$ \\
\hline Scinax fuscomarginatus (A. Lutz, 1925) & Sfsm & 9,36 & 272 & 50 & $\mathrm{~T}, \mathrm{VE}, \mathrm{H}$ \\
\hline Scinax fuscovarius (A. Lutz, 1925) & $S f s v$ & 20,92 & 500 & 45,8 & $\mathrm{~S}, \mathrm{VE}, \mathrm{H}, \mathrm{AB}$ \\
\hline Scinax similis (Cochran, 1952) & Ssim & 2,56 & 100 & 25 & VE, $\mathrm{H}$ \\
\hline Scinax squalirostris (A. Lutz, 1925) & Ssqu & 0,30 & 15 & 21 & $\mathrm{H}$ \\
\hline \multicolumn{6}{|l|}{ Leiuperidae } \\
\hline Eupemphix nattereri Steindachner, 1863 & Enat & 0,10 & 5 & 17 & $\mathrm{~L}$ \\
\hline Physalaemus centralis Bokermann, 1962 & Pcen & 1,11 & 50 & 17 & $\mathrm{~L}$ \\
\hline Physalaemus cuvieri Fitzinger, 1826 & Pcuv & 5,94 & 200 & 62,5 & $\mathrm{~L}$ \\
\hline Physalaemus marmoratus (Reinhardt \& Lütken, 1862 “1861”) & Pmar & 0,49 & 25 & 13 & $\mathrm{~L}$ \\
\hline \multicolumn{6}{|l|}{ Leptodactylidae } \\
\hline Leptodactylus fuscus (Schneider, 1799) & Lfus & 3,22 & 140 & 38 & $\mathrm{~S}$ \\
\hline Leptodactylus labyrinthicus (Spix, 1824) & Llab & 0,12 & 2 & 25 & $\mathrm{~L}$ \\
\hline Leptodactylus latrans (Steffen, 1815) & Llat & 0,04 & 1 & 13 & $\mathrm{~S}$ \\
\hline Leptodactylus mystaceus (Spix, 1824) & Lmce & 0,80 & 50 & 13 & $\mathrm{~S}$ \\
\hline Leptodactylus mystacinus (Burmeister, 1861) & Lmcy & 1,76 & 70 & 29,2 & $\mathrm{~S}$ \\
\hline \multicolumn{6}{|l|}{ Microhylidae } \\
\hline Chiasmocleis albopunctata (Boettger, 1885) & Calb & 0,43 & 40 & 4 & $\mathrm{~L}$ \\
\hline Elachistocleis ovalis (Schneider, 1799) & Eova & 2,88 & 130 & 33,3 & $\mathrm{~L}$ \\
\hline
\end{tabular}

*Espécie encontrada fora do período de estudo. Abundância relativa (AR), abundância máxima (AM), constância de ocorrência (C) e substrato de vocalização (S - solo; T - taboa; Ve - vegetação emergente; H - vegetação herbácea; Ab - vegetação arbustiva; L - lâmina d'água).

*Species found outside the study period. Relative abundance (AR), maximum abundance (AM), constancy of occurrence (C), and calling substrate ( $\mathrm{S}$ - ground, T - Typhaceae; Ve - emergent vegetation; $\mathrm{H}$ - herbaceous vegetation, Ab - shrubby vegetation; $\mathrm{L}$ - water surface).

ao período de maior precipitação. Esses dados concordam com o exposto por Giaretta et al. (2008), de que as espécies de Cerrado são fortemente influenciadas pelos fatores climáticos, reproduzindo-se principalmente durante a estação chuvosa. Bernarde \& Kokubum (1999) e Vasconcelos \& Rossa-Feres (2005) também obtiveram correlação positiva entre número de espécies em atividade de vocalização e a precipitação em estudos com anuros em áreas de transição de Cerrado e Floresta Estacional Semidecidual. Apesar de ser considerado período seco, o mês de agosto de ambos os anos tiveram altos índices de precipitação, o que pode ter influenciado o início da atividade reprodutiva de várias espécies. Em regiões de clima sazonal a chuva tem relação direta com a umidade do ar, que é fator determinante no período de atividade dos anuros, além disso, a precipitação disponibiliza ou renova sítios reprodutivos (Rossa-Feres \& Jim 1994).

A temperatura atuou como fator secundário na atividade das espécies, estando os meses das menores riquezas e abundâncias associados com as menores temperaturas mínimas. Eterovick
\& Sazima (2000) expõem que embora a temperatura tenha uma importância secundária, as baixas temperaturas possam ser usadas como um sinal do término da estação chuvosa. Jim (2003) relata que a temperatura tem um papel importante no início da atividade de algumas espécies. Os meses com os maiores aumentos de temperatura contribuíram tanto no aumento da riqueza, quanto na abundância. Uma exceção foi setembro de 2008, no entanto a baixa precipitação nesse mês também pode ter influenciado na atividade de algumas espécies.

As únicas espécies que tiveram seus períodos de vocalização fora da estação chuvosa foram Rhinella ornata e Odontophrynus americanus. Essa última teve um único e curto período com machos em atividade de vocalização. O registro foi feito após uma forte chuva $(28,3 \mathrm{~mm}$ em uma manhã) em uma depressão em área de campo com touceiras ao lado da lagoa. No mês seguinte ainda foram registrados girinos da espécie no local. Comportamento idêntico foi encontrado por Eterovick \& Sazima (2000) na Serra do Cipó, onde O. americanus 


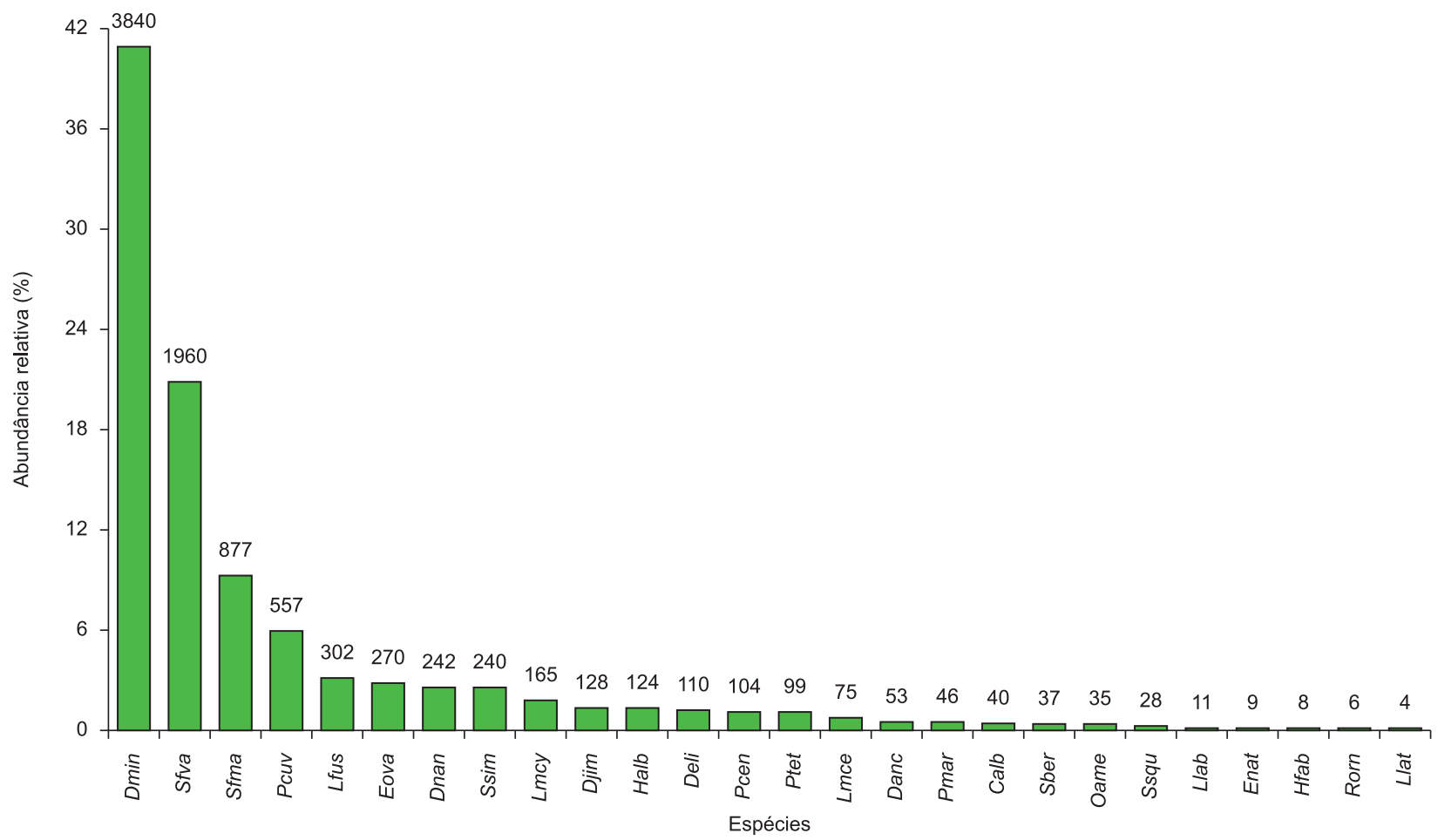

Figura 5. Abundância relativa das 26 espécies de anuros registradas na Fazenda Rio Pardo, município de Borebi, entre janeiro de 2008 e dezembro de 2009. As barras representam a abundância relativa das espécies (\%), enquanto os valores em seus topos representam o número total de registros. Abreviações dos nomes das espécies de acordo com a Tabela 1.

Figure 5. Relative abundance of the 26 recorded anuran species in the Rio Pardo Farm, municipality of Borebi, between January 2008 and December 2009. The bars represent the relative abundance of species (\%), while the values at their tops represent the total number of records. Abbreviations of species names according to Table 1.

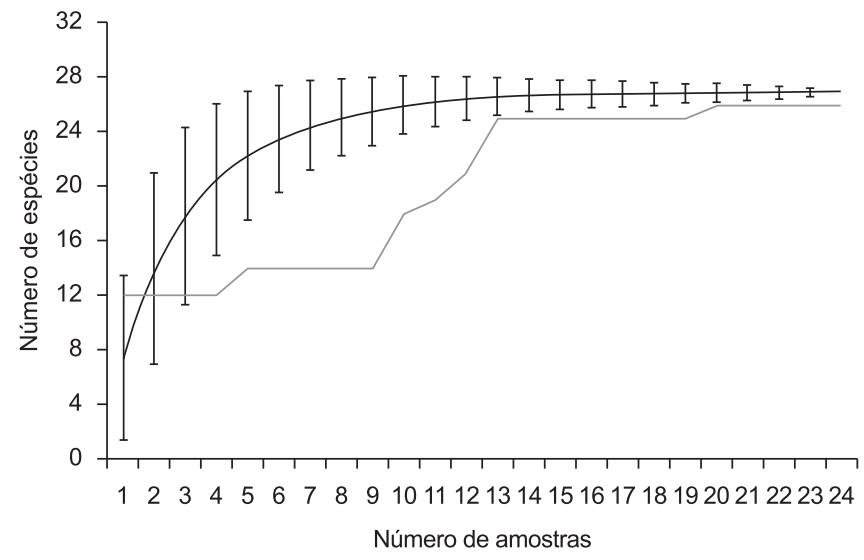

Figura 6. Curvas de riqueza observada (cinza) e de riqueza média estimada pelo método Bootstrap (preto) com as barras verticais indicando os respectivos desvios-padrão nas 24 amostras.

Figure 6. Observed richness (gray) and mean richness curves estimated by Bootstrap (black). Vertical bars indicate the standard-deviations for 24 samples.

iniciou sua atividade reprodutiva somente com o enchimento de uma poça pela água da chuva.

Os hilídeos tiveram um período de reprodução mais longo que as espécies pertencentes às demais famílias. Leptodactilídeos e leiuperídeos encerraram o período de reprodução após o período chuvoso, sendo que nenhum indivíduo foi registrado vocalizando nos meses frios e secos, evidenciando um comportamento altamente sazonal das espécies dessas famílias. Esses resultados podem estar relacionados com o local e o modo reprodutivo dessas famílias. Como leptodactilídeos e leiuperídeos utilizaram para reprodução as áreas encharcadas ao redor da lagoa, esses locais dependem de acúmulo de água da chuva. As espécies registradas dessas duas famílias depositam seus ovos em ninhos de espuma (aquáticos ou em tocas subterrâneas) e as larvas completam seu desenvolvimento em poças (Pombal Junior \& Haddad 2007). Portanto, com o fim do período chuvoso, há o risco dos encharcados secarem e interromperem o desenvolvimento das larvas (Giaretta \& Facure 2006). Evento desse tipo é citado por Santos et al. (2007) no noroeste do estado de São Paulo, região com inconstância de chuvas que ocasiona a instabilidade dos corpos d'água. Iniciando a reprodução com o início das chuvas também pode evitar a infestação do ninho por moscas, mais abundantes no final da estação chuvosa (Giaretta \& Facure 2006).

O hidroperíodo do corpo d'água também pode influenciar o comportamento dos indivíduos. Espécies que normalmente vocalizam empoleiradas (e.g., Dendropsophus minutus), foram registradas vocalizando no solo no período mais seco. Isso se deve à ausência de vegetação marginal nos períodos mais secos, quando a área da lâmina d'agua reduz consideravelmente.

Apesar do plano vertical ser pouco diversificado em áreas abertas, metade das espécies registradas pertenceu a representantes da família Hylidae. Essa dominância da família Hylidae em área aberta é comum em estudos em áreas de Mata Atlântica (Pombal Junior 1997, Prado \& Pombal Junior 2005, Abrunhosa et al. 2006). Já em nas áreas de Cerrado do interior paulista a riqueza de hilídeos representa menos da metade da comunidade (Brasileiro et al. 2005, Vasconcelos \& Rossa-Feres 2005). A presença de discos adesivos nos hilídeos possibilita a ocupação vertical do hábitat aumentando, deste modo, a segregação espacial (Cardoso et al. 1989). A principal vegetação próxima ao corpo d'água é formada de emergentes e herbáceas, que suportam em seus poleiros apenas espécies de pequeno porte. Nesse 


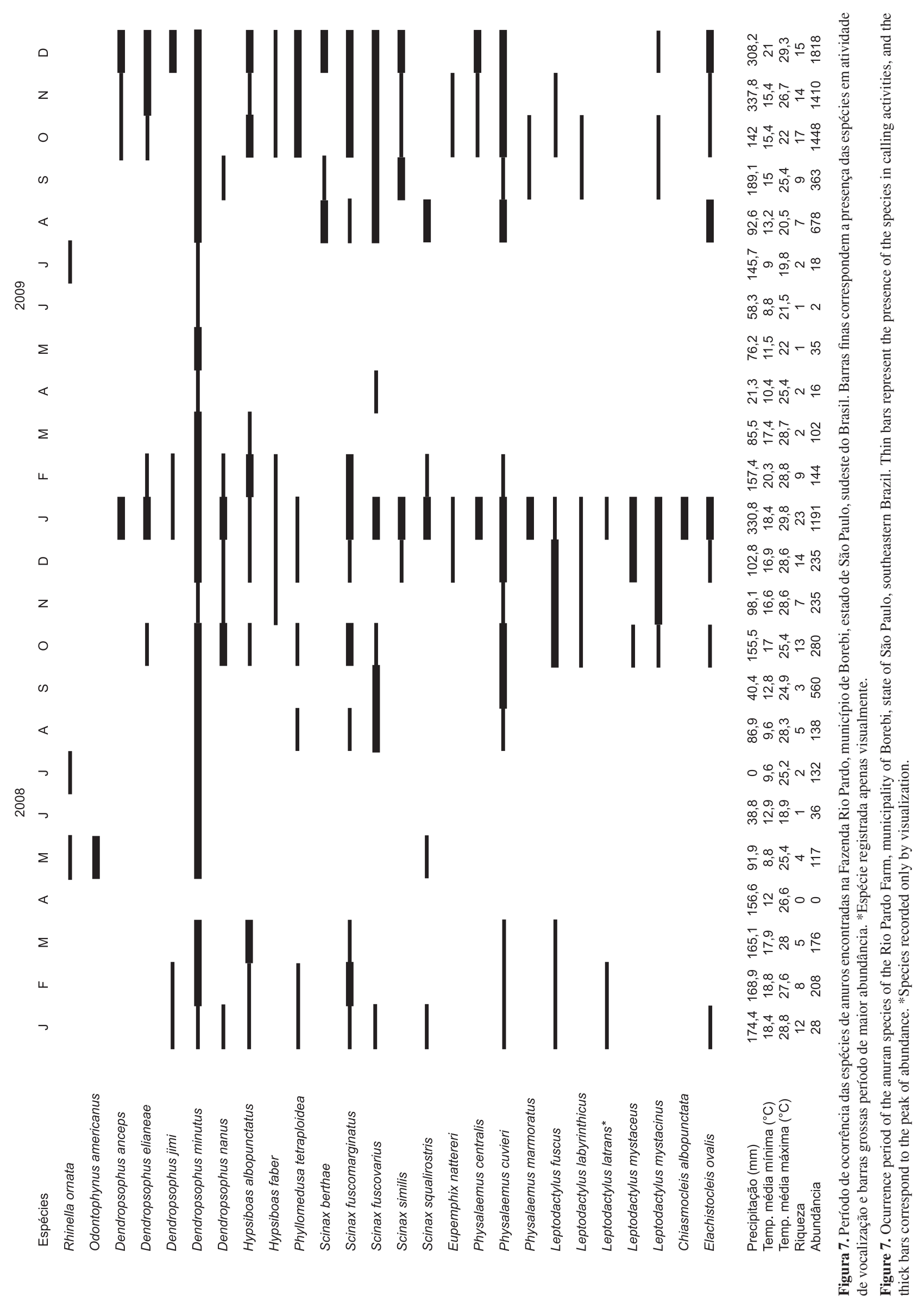


caso o uso do hábitat diferenciado entre hilídeos grandes e pequenos pode ser explicado pelo tamanho e massa das espécies (Duellman 1967). Conforme a vegetação se distancia da lagoa, ficando mais resistente, com poleiros mais rígidos, favorece espécies maiores como Hypsiboas albopunctatus, H. faber e Phyllomedusa tetraploidea, sendo que essas duas últimas usam o estrato vertical de diversas maneiras, vocalizando até próximo ao solo. Essa segregação no sítio de vocalização entre os hilídeos também foi registrada por Conte \& Rossa-Feres (2007) e Prado \& Pombal Junior (2005). A riqueza ou a coexistência de espécies está diretamente ligada com a capacidade de exploração dos microambientes com características distintas (Jim 1980, Cardoso et al.1989, Rossa-Feres \& Jim 2001).

A riqueza em áreas abertas localizadas em áreas de transição supera a riqueza encontrada em locais com fitofisionomias florestais - Cerradão e Floresta Estacional Semidecidual (Araujo et al. 2009b). Apesar da aparente homogeneidade física do ambiente aberto, a lagoa amostrada possui diversos microambientes formados conforme a alteração do seu volume de água. Espécies de área aberta são menos especializadas e geralmente o número de espécies de área aberta é maior do que o número de microambientes disponíveis (Cardoso et al. 1989, Jim 1980 e 2003). No presente estudo, isso é mostrado pelas espécies terrestres, principalmente leiuperídeos e leptodactilídeos que utilizaram os mesmos microambientes na lagoa e na poça temporária. Mesmo com vários microambientes disponíveis na borda da lagoa, as espécies dessas duas famílias preferiram a poça temporária para vocalização. Uma possível explicação para essa mudança de ambiente é a ausência ou menor abundância de predadores de girinos no ambiente temporário, proporcionando um maior sucesso reprodutivo (Woodward 1983).

Essa alta riqueza e abundância de anuros da lagoa estudada pode ser resultado de vários fatores: a) ausência de outros corpos d'água - em um raio de quatro quilômetros não existem corpos d'água permanentes. Visto que a dispersão e o deslocamento de anfíbios não são grandes (Smith \& Green 2005), a ausência de ambientes permanentes em área aberta próximos da lagoa colaboram para a presença dos anuros no ambiente; b) ausência de peixes predadores - o único peixe encontrado na lagoa é o muçum (Synbranchus marmoratus) que não apresenta girinos em sua dieta (Silva 1993, Braga et al. 2008). A presença de somente essa espécie de peixe na lagoa pode ser resultado do fato da lagoa secar em determinados anos. O muçum tolera baixos níveis de oxigênio e pode entrar em um processo de semi-estivação, sobrevivendo até três meses enterrados na lama (Bicudo \& Johansen 1979). A presença de peixes predadores é relacionada negativamente com a presença de determinadas espécies de anfíbios (Heyer et al. 1975, Hero et al. 2001), e c) formação de diferentes microambientes - apesar de ser uma lagoa do tipo açude, conforme a lâmina d'água reduz ou aumenta, vários pontos nas margens tomam características de brejos, poças semi-permanentes e áreas alagadas. Essa frequente mudança no ambiente disponibiliza inúmeras opções a serem exploradas pelas espécies e quanto maior o número de microambientes de reprodução, maior a riqueza de anuros (Haddad \& Prado 2005).

Estudos em áreas de Cerrado são extremamente importantes, visto que este bioma vem sofrendo com altas taxas de perda de biodiversidade pela ocupação humana e expansão da agricultura
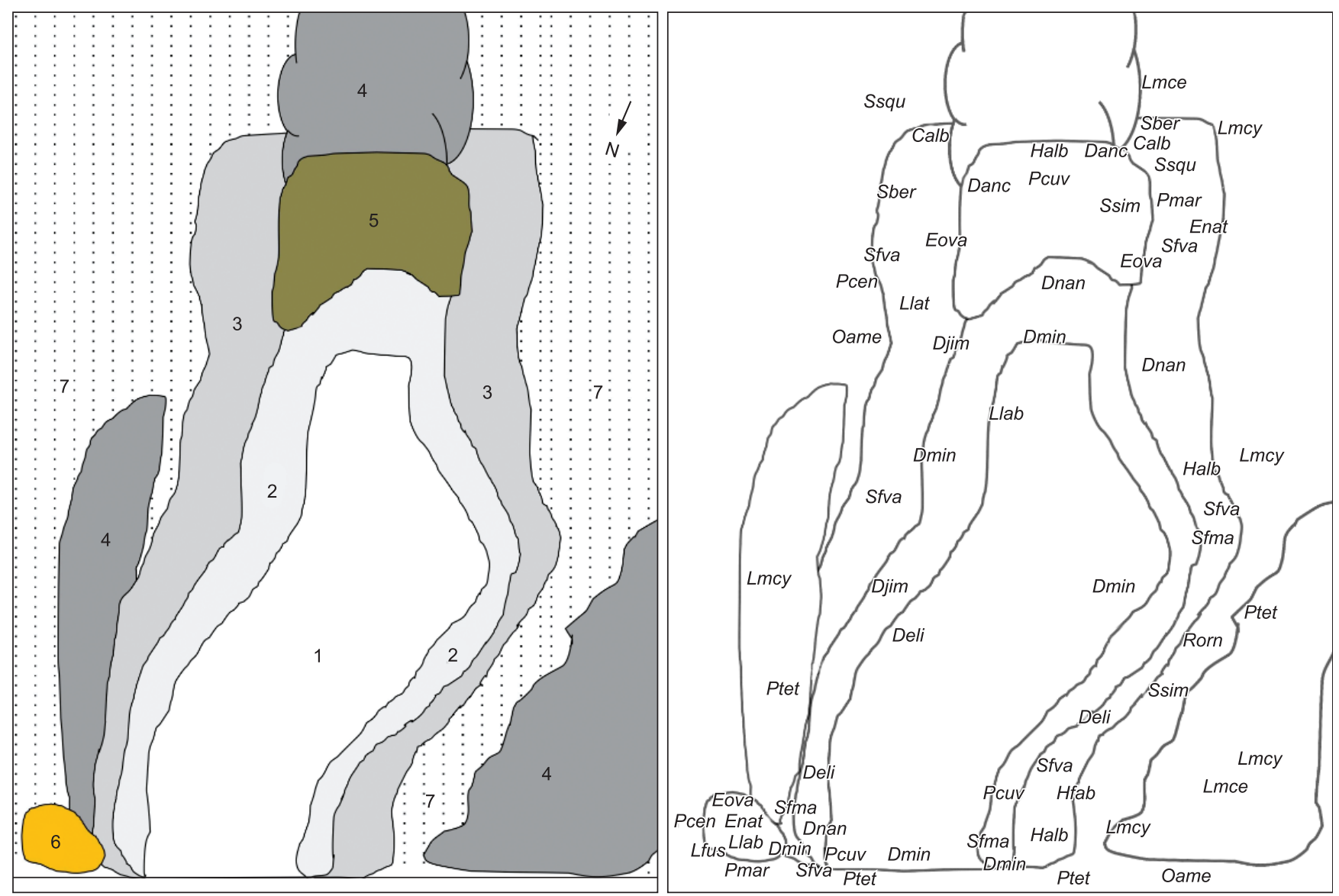

Figura 8. Representação esquemática da área de estudo demostrando os diferentes ambientes utilizados pelos anuros: 1) lâmina d'água; 2) vegetação emergente; 3) vegetação herbácea; 4) vegetação arbórea-arbustiva; 5) taboal; 6) poça temporária; e 7) vegetação herbáceo-arbustiva.

Figure 8. Schematic representation of the study area showing the different environments occupied by anurans: 1) water surface; 2) emergent vegetation; 3) herbaceous vegetation; 4) arboreal-shrubby vegetation; 5) Thyphaceae; 6) temporary pond; and 7) herbaceous-shrubby vegetation. 
(Klink \& Moreira 2002). O conhecimento sobre comunidades de anfíbios anuros em áreas de Cerrado é escasso (Bastos 2007) e no estado de São Paulo apenas um estudo foi realizado em áreas de cerrado aberto (Brasileiro et al. 2005). A área estudada é considerada prioritária para a conservação do Cerrado paulista (São Paulo 1997), sendo que as áreas de formação aberta são as mais atingidas e estratégias de conservação para esses locais devem ser postas em prática urgentemente (Silva \& Bates 2002).

Estudos recentes conduzidos na região do presente estudo revelaram novas ocorrências de espécies de anuros (Rolim et al. 2008, 2010, Almeida et al. 2008, Maffei et al. 2009), o que pode ser reflexo da baixa quantidade de estudos desenvolvidos nessas áreas. Ainda que o estado de São Paulo seja uma das regiões mais estudadas do Brasil no que diz respeito à riqueza de espécies e distribuição dos anfíbios (Araújo et al. 2009a), fica evidente a existência de uma lacuna no que tange ao conhecimento da anurofauna na região centro-oeste do estado. Dessa forma, o presente estudo acrescenta uma contribuição substancial no conhecimento da anurofauna do Cerrado paulista.

\section{Agradecimentos}

Os autores agradecem à Duratex S.A. pelo apoio financeiro e logístico e pelo fornecimento dos dados climáticos, à FUNDIBIO pelas bolsas de estudo e ao Instituto Chico Mendes de Conservação da Biodiversidade pela licença de coleta (IBAMA/ICMBio/SISBIO 16778-1). Daniel C. Rolim e Maria G. Teixeira pelas críticas na versão preliminar. Maria Estela S. Paschoal pelo auxílio na caracterização vegetal da área de estudo. Roger F. Vicente, Guilherme M. Moya, Cesar A. B. Medolago, Domingos Garrone-Neto, Sílvio C. Almeida, William P. da Costa e Anderson Lucindo colaboraram nos trabalhos de campo.

\section{Referências Bibliográficas}

ABRUNHOSA, P.A., WOGEL, H. \& POMBAL JUNIOR, J.P. 2006. Anuran temporal occupancy in a temporary pond from the Atlantic Rain Forest, South-Eastern Brazil. Herpetol. J. 16:115-122.

ALMEIDA, S.C., MAFFEI, F., ROLIM, D.C., UBAID, F.K. \& JIM, J. 2008. Amphibia, Anura, Hylidae, Sphaenorhynchus caramaschii: Distribution extension in state of São Paulo, Brazil. Check List 4(4):439-441.

ARAÚJO, O.G.S., TOLEDO, L.F., GARCIA, P.C.A. \& HADDAD C.F.B. 2009a. Lista de Anfíbios do Estado de São Paulo. Biota Neotrop. 9(4): http://www.biotaneotropica.org.br/v9n4/pt/abstract?inventory+ bn03109042009 (último acesso em 01/05/2010).

ARAUJO, C.O., CONDEZ, T.H. \& SAWAYA, R.J. 2009b. Anfíbios Anuros do Parque Estadual das Furnas do Bom Jesus, sudeste do Brasil, e suas relações com outras taxocenoses no Brasil. Biota Neotrop. 9(2): http:// www.biotaneotropica.org.br/v9n2/pt/abstract?article+bn01109022009 (último acesso em 01/05/2010).

AYRES, M., AYRES JUNIOR, M., AYRES, D.L. \& SANTOS, A.A. 2007. BioEstat: aplicações estatísticas nas áreas das ciências biológicas e médicas. Sociedade Civil Mamirauá, MCT-CNPq, Belém.

BALDISSERA JUNIOR, F.A., CARAMASCHI, U. \& HADDAD, C.F.B. 2004. Review of the Bufo crucifer species group, with descriptions of two new related species (Amphibia, Anura, Bufonidae). Arq. Mus. Nac. 62(3):255-282.

BASTOS, R.P. 2007. Anfíbios do Cerrado. In Herpetologia no Brasil II (L.B. Nascimento \& M.E. Oliveira, orgs.). Sociedade Brasileira de Herpetologia, Belo Horizonte, p.87-100.

BERNARDE, P.S. \& KOKUBUM, M.N.C. 1999. Anurofauna do Município de Guararapes, Estado de São Paulo, Brasil (Amphibia: Anura). Acta Biol. Leopoldensia. 21(1):89-97.

BICUDO, J.P.W. \& JOHANSEN, K. 1979. Respiratory gas exchange in the airbreathing fish, Synbranchus mamoratus. Env. Biol. Fish. 4(1):55-64. http://dx.doi.org/10.1007/BF00005928

BRAGA, A.L.C., POMPEU, P.S., CARVALHO, R.F. \& FERREIRA, R.F. 2008. Dieta e crescimento de Synbranchus marmoratus (Bloch, 1975) (Pisces, Synbranchiformes) durante período de pré-estivação em uma lagoa marginal da bacia do São Francisco, Minas Gerais. Rev. Bras. Zoociênc. 10(2):133-138.
BRASILEIRO, C.A., SAWAYA, R.J., KIEFER, M.C. \& MARTINS, M. 2005. Amphibians of an open cerrado fragment in southeastern Brazil. Biota Neotrop. 5(2): http://www.biotaneotropica.org.br/v5n2/ pt/abstract?article+BN00405022005 (último acesso em 01/05/2010).

CARDOSO, A.J., ANDRADE, G.V.\& HADDAD, C.F.B. 1989. Distribuição espacial em comunidades de anfíbios (Anura) no sudeste do Brasil. Rev. Bras. Biol. 49(1):241-249.

CARPANEZZI, A.A., KINJO, T. \& POGGIANI, F. 1975. Estudos Básicos sobre a Ecologia da Floresta Tropical Latifoliada Semidecídua e Formações Anexas na Região de Lençóis Paulista, Estado de São Paulo. Relatório de Pesquisa. ESALQ-USP, Piracicaba.

CENTRO DE REFERÊNCIA EM INFORMAÇÃO AMBIENTAL - CRIA. 2009. Atlas do Programa BIOTA/FAPESP. http://sinbiota.cria.org.br/ atlas (último acesso em 11/03/2010).

COLLI, G.R., BASTOS, R.P. \& ARAÚJO, A.F.B. 2002. The character and dynamics of the Cerrado herpetofauna. In The Cerrados of Brazil: Ecology and Natural History of a Neotropical Savanna (P.S. Oliveira \& R.J. Marquis, eds.). Columbia University Press, New York, p.223-241.

COLWELL, R.K. 2005. EstimateS: statistical estimation of species richness and shared species from samples. Versão 7.5.2. http://viceroy.eeb.uconn. edu/estimates (último acesso em 9/10/2009).

CONTE, C.E. \& ROSSA-FERES, D.C. 2007. Riqueza e distribuição espaço-temporal de anuros em um remanescente da Floresta de Araucária no sudeste do Paraná. Rev. Bras. Zool. 24(4):1025-1037. http://dx.doi. org/10.1590/S0101-81752007000400020

CRUMP, M.L. \& SCOTT JUNIOR, N.J. 1994. Standard techniques for inventory and monitoring: visual encounter surveys. In Measuring and monitoring biological diversity: standard methods for amphibians (W.R. Heyer, M.A. Donnelly, R.W. McDiarmid, L.A.C. Hayek \& M.S. Foster, eds.). Smithsonian Institution Press, Washington, p.84-92.

DAJOZ, R. 1972. Ecologia Geral. Vozes, Petrópolis; Universidade de São Paulo, São Paulo.

DUELLMAN, W.E. 1967. Courtship isolating mechanisms in Costa Rica hylids frogs. Herpetologica. 23(3):169-183.

DUELLMAN, W.E. 1999. Distribution patterns of amphibians in South America. In Patterns of Distribution of Amphibians (W.E. Duellman, ed.) The Johns Hopkins University Press, Baltimore and London, p. 255-327.

DURIGAN, G., FRANCO, G.A.D.C. \& SIQUEIRA, M.F. 2004. A vegetação dos remanescentes de cerrado no Estado de São Paulo. In Viabilidade de conservação dos remanescentes de cerrado no Estado de São Paulo (M.D. Bitencourt \& R.R. Mendonça, org.). Annablume, Fapesp, São Paulo, p.29-56.

EITEN, G. 1972. The Cerrado vegetational of Brazil. Bot. Rev. 38:201-341. http://dx.doi.org/10.1007/BF02859158

ETEROVICK, P.C. \& SAZIMA, I. 2000. Structure of an anuran community in a montane meadow in southeastern Brazil: effects of seasonality, habitat, and predation. Amphibia-Reptilia 21(4):439-461. http://dx.doi. org/10.1163/156853800300059331

FROST, D.R. 2010. Amphibian Species of the World: an Online Reference. American Museum of Natural History, New York. Version 5.4. http:// research.amnh.org/herpetology/amphibia/index.php (último acesso em 01/05/2010).

GIARETTA, A.A. \& FACURE, K.G. 2006. Terrestrial and communal nesting in Eupemphix nattereri(Anura, Leiuperidae): interactions with predators and pond structure. J. Nat. Hist. 40(44-46):2577-2587. http://dx.doi. org/10.1080/00222930601130685

GIARETTA, A.A., MENIN, M., FACURE, K.G., KOKUBUM, M.N.C. \& De OLIVEIRA FILHO, J.C. 2008. Species richness, relative abundance, and habitat of reproduction of terrestrial frogs in the Triangulo Mineiro region, Cerrado biome, southeastern Brazil. Iheringia, Sér. Zool. 98(2):181-188.

GOTTSBERGER, G. \& SILBERBAUER-GOTTSBERGER, I. 2006. Life in the cerrado: a South American tropical seasonal vegetation. Reta Verlag, Ulm, v.1 Origin, structure, dynamics and plant use, 277p.

HADDAD, C.F.B. 1998. Biodiversidade dos anfíbios do Estado de São Paulo. In Biodiversidade do Estado de São Paulo, Brasil: síntese do conhecimento ao final do século XX (R.M.C. Castro, ed.). FAPESP, São Paulo, v.6, p.17-26.

HADDAD, C.F.B. \& PRADO, C.P.A. 2005. Reproductive modes in frogs and their unexpected diversity in the Atlantic forest of Brazil. BioScience. 55(3):207-217. http://dx.doi.org/10.1641/0006-3568(2005)055[0207:RM IFAT]2.0.CO;2

HERO, J.M., MAGNUSSON, W.E., ROCHA, C.F.D. \& CATTERALL, C.P. 2001. Antipredator defenses influence the distribution of amphibian prey species in the central Amazon rainforest. Biotropica. 33(1):131-141. 
HEYER, W.R., McDIARMID, R.W. \& WEIGMANN, D.L. 1975. Tadpoles, predation and pond habitats in the tropics. Biotropica. 7:100-111. http://dx.doi.org/10.2307/2989753

JIM, J. 1980. Aspectos ecológicos dos anfíbios registrados na região de Botucatu, São Paulo (Amphibia, Anura). Tese de Doutorado, Universidade de São Paulo, São Paulo.

JIM, J. 2003. Distribuição altitudinal e estudo de longa duração de anfíbios da região de Botucatu, Estado de São Paulo. Tese de Livre-Docência, Instituto de Biociências de Botucatu, Universidade Estadual Paulista.

KLINK, C.A. \& MACHADO, R.B. 2005. Conservation of the Brazilian cerrado. Conserv. Biol. 19(3):707-713. http://dx.doi.org/10.1111/j.15231739.2005.00702.x

KLINK, C.A. \& MOREIRA, A.G. 2002. Past and current human occupation and land-use. In The Cerrados of Brazil: Ecology and Natural History of a Neotropical Savanna (P.S. Oliveira \& R.J. Marquis, eds.). Columbia University Press, New York, p.69-88.

KRONKA, F.J.N., NALON, M.A., MATSUKUMA, C.K., KANASHIRO, M.M., YWANE, M.S.S., LIMA, L.M.P.R., GUILLAUMON, J.R., BARRADAS, A.M.F., PAVÃO, M., MANETTI, L.A. \& BORGO, S.C. 2005. Monitoramento da vegetação natural e do reflorestamento no Estado de São Paulo. In XII Simpósio Brasileiro de Sensoriamento Remoto. Instituto Nacional de Pesquisas Espaciais, Goiânia, p.1569-1576.

KRONKA, F.J.N., NALON, M.A., MATSUKUMA, C.K., PAVÃO, M., GUILLAUMON, J.R., CAVALLI, A.C., GIANNOTTI, E., IWANE, M.S.S., LIMA, L.M.P.R., MONTES, J., DEL CALI, I.H. \& HAACK, P.G. 1998. Áreas de domínio de Cerrado no Estado de São Paulo. Secretaria de Estado do Meio Ambiente, Instituto Florestal, São Paulo, 84p.

MACHADO, R.B., RAMOS NETO, M.B., PEREIRA, P.G.P., CALDAS, E., GONÇALVES, D.A., SANTOS, N.S., TABOR, K. \& STEININGER, M. 2004. Estimativas de perda da área do Cerrado brasileiro. Relatório técnico, Conservação Internacional Brasil, Brasília.

MAFFEI, F., UBAID, F.K., ALMEIDA, S.C., ROLIM, D.C., SCARPELLINI-JUNIOR., D. G., MOYA, G.M., SPIRANDELLI-CRUZ, E.F. \& JIM, J. 2009. Amphibia, Anura, Hylidae, Dendropsophus microps (Peters, 1872): Distribution extension in state of São Paulo, Brazil and first record in Cerrado domain. Check List 5(4):776-779.

MAGURRAN, A.E. 1988. Ecological diversity and its measurement. Princeton University Press, New Jersey, 179p.

MELO, G.V., ROSSA-FERES, D.C. \& JIM, J. 2007. Variação temporal no sítio de vocalização em uma comunidade de anuros de Botucatu, Estado de São Paulo, Brasil. Biota Neotrop. 7(2): http://www. biotaneotropica.org.br/v7n2/pt/abstract?article+bn01707022007 (último acesso em 01/05/2010).

MORAES, R.A., SAWAYA, R.J. \& BARRELA, W. 2007. Composição e diversidade de anfíbios anuros em dois ambientes de Mata Atlântica no Parque Estadual Carlos Botelho, São Paulo, sudeste do Brasil. Biota Neotrop. 7(2): http://www.biotaneotropica.org.br/v7n2/pt/ abstract?article+BN00307022007 (último acesso em 29/08/2009).

MYERS, N., MITTERMEIER, R.A., MITTERMEIER, C.G., FONSECA, G.A.B. \& KENT, J. 2000. Biodiversity hotspots for conservation priorities. Nature. 403:853-858. PMid:10706275. http://dx.doi. org/10.1038/35002501

NAPOLI, M.F. \& CARAMASCHI, U. 1999. Variation and description of two new Brazilian Hyla of the H. tritaeniata complex (Amphibia, Anura, Hylidae). Bol. Mus. Nac. Zoologia 407:1-11

POMBAL JUNIOR, J.P. 1997. Distribuição espacial e temporal de anuros (Amphibia) em uma poça permanente na Serra de Paranapiacaba, sudeste do Brasil. Rev. Bras. Biol. 57(2):583-594.

POMBAL JUNIOR, J.P. \& HADDAD, C.F.B. 2007. Estratégias e modos reprodutivos em anuros. In Herpetologia no Brasil II (L.B. Nascimento \& P.M.E. Oliveira, eds.). Sociedade Brasileira de Herpetologia, Belo Horizonte, p.101-116.

PRADO, G.M. \& POMBAL JUNIOR, J.P. 2005. Distribuição espacial e temporal dos anuros em um brejo da Reserva Biológica de Duas Bocas, Sudeste do Brasil. Arq. Mus. Nac. 63(4):685-705.

RATTER, J.A., RIBEIRO, J.F. \& BRIDGEWATER, S. 1997. The Brazilian cerrado vegetation and threats to its biodiversity. Ann. Bot. 80(3):223-230. http://dx.doi.org/10.1006/anbo.1997.0469
RIBEIRO JUNIOR, J.W. \& BERTOLUCI, J. 2009. Anuros do cerrado da Estação Ecológica e da Floresta Estadual de Assis, sudeste do Brasil. Biota Neotrop. 9(1): http://www.biotaneotropica.org.br/v9n1/pt/abstrac t?inventory+bn02709012009 (último acesso em 31/08/2009).

RODRIGUES, D.J., UETANABARO, M. \& LOPES, F.S. 2005. Reproductive patterns of Trachycephalus venulosus (Laurenti, 1768) and Scinax fuscovarius (Lutz, 1925) from the Cerrado, Central Brazil. J. Nat. Hist. 39(35):3217-3226. http://dx.doi.org/10.1080/00222930500312244

ROLIM, D.C., MAFFEI, F., SENE, R.K., MEDOLAGO, C.A.B., VERNINI, T.H., UBAID, F.K. \& JIM, J. 2008. Amphibia, Anura, Hylidae, Dendropsophus anceps: Distribution extension in state of São Paulo, Brazil. Check List. 4(3):358-361.

ROLIM, D.C., MARTINEZ, R.A.M., ALMEIDA, S.C., UBAID, F.K., MAFFEI, F. \& JIM, J. 2010. Amphibia, Anura, Cycloramphidae, Proceratophrys moratoi (Jim and Caramaschi, 1980): Distribution extension and new altitudinal record in state of São Paulo, Brazil. Check List. 6(4):576-578.

ROSSA-FERES, D.C. \& JIM, J. 1994. Distribuição sazonal em comunidades de anfíbios anuros na região de Botucatu, São Paulo. Rev. Bras. Biol. 54(2):323-334.

ROSSA-FERES, D.C. \& JIM, J. 2001. Similaridade do sítio de vocalização em uma comunidade de anfíbios anuros na região noroeste do Estado de São Paulo, Brasil. Rev. Bras. Zool. 18(2):439-454. http:// dx.doi.org/10.1590/S0101-81752001000200015

SANTOS, A.J. 2003. Estimativas de riqueza em espécies. In Métodos de estudos em biologia da conservação e manejo da vida silvestre (L. Cullen Junior, R. Rudran \& C.Valladares-Pádua, eds.). Editora da UFPR, Curitiba, p.19-41.

SANTOS, T.G., ROSSA-FERES, D.C. \& CASATTI, L. 2007. Diversidade e distribuição espaço-temporal de anuros em região com pronunciada estação seca no sudeste do Brasil. Iheringia, Sér. Zool. 97(1):37-49.

SÃO PAULO (Estado). Secretaria de Estado do Meio Ambiente - SMA. 1997. Bases para Conservação e Uso Sustentável do Cerrado Paulista. Programa Estadual para a Conservação da Biodiversidade-Probio. http://eco.ib.usp. br/lepac/biota-cerrado/cartaz.pdf (último acesso em 01/05/2010).

SILVA, C.P.D. 1993. Alimentação e distribuição espacial de algumas espécies de peixes do igarapé do Candirú, Amazonas, Brasil. Acta Amazonica. 23:271-285

SILVA, J.M.C. \& BATES, J.M. 2002. Biogeographic patterns and conservation in the South American cerrado: a tropical savanna hotspot. BioScience. 52:225-233. http://dx.doi.org/10.1641/0006-3568(2002)052[0225:BPA CIT]2.0.CO;2

SMITH, M.A. \& GREEN, D.M. 2005. Dispersal and the metapopulation paradigm in amphibian ecology and conservation: are all amphibian populations metapopulations? Ecography 28:110-128. http://dx.doi. org/10.1111/j.0906-7590.2005.04042.x

SMITH, E.P. \& van BELLE, G. 1984. Nonparametric estimation of species richness. Biometrics 40:119-129. http://dx.doi.org/10.2307/2530750

VASCONCELOS, T.S. \& ROSA-FERES, D.C. 2005. Diversidade, distribuição espacial e temporal de anfíbios anuros (Amphibia, Anura) na região noroeste do estado de São Paulo. Biota Neotrop. 5(2): http:// www.biotaneotropica.org.br/v5n2/pt/abstract?article+BN01705022005 (último acesso em 15/07/2009).

VASCONCELOS, T.S., SANTOS, T.G., HADDAD, C.F.B. \& ROSSAFERES, D.C. 2010. Climatic variables and altitude as predictors of anuran species richness and number of reproductive modes in Brazil. J. Trop. Ecol. 26:423-432. http://dx.doi.org/10.1017/S0266467410000167

VITT, L.J., CALDWELL, J.P., COLLI, G.R., GARDA, A.A., MESQUITA, D.O., FRANÇA, F.G.R., SHEPARD, D.B., COSTA, G.C., VASCONCELLOS, M.M. \& SILVA, V.N. 2005. Uma Atualização do Guia Fotográfico dos Répteis e Anfíbios da Região do Jalapão no Cerrado Brasileiro. Spec. Publ. Herpetol., Sam Noble Okla. Mus. Nat. Hist. 2:1-24.

WOODWARD, B.D. 1983. Predator-prey interactions and breeding pond use of temporary-pond species in a desert anuran community. Ecology 64(6):1549-1555. http://dx.doi.org/10.2307/1937509

ZIMMERMAN, B.L. 1994. Audio Strip Transects. In Measuring and Monitoring Biological Diversity: Standard Methods for Amphibians (W.R. Heyer, M.A. Donnelly, R.W. McDiarmid, L.A.C. Hayek \& M.S. Foster, eds.). Smithsonian Institution Press, Washington, p. 92-97. 


\section{Apêndice}

Apêndice 1. Espécies de anfíbios coletadas no município de Borebi, SP. O número associado a cada espécime corresponde ao número de tombo na Coleção Científica Jorge Jim.

Appendix 1. Species of amphibians collected at municipality of Borebi, SP. The number associated with each specimen corresponds to number in Jorge Jim Scientific Collection.

Chiasmocleis albopunctata (7877), Dendropsophus anceps (7899), Dendropsophus elianeae (7902), Dendropsophus jimi (7893), Dendropsophus minutus (7874), Dendropsophus nanus (7879), Elachistocleis ovalis (7864), Eupemphix nattereri (7895), Hypsiboas albopunctatus (7869), Hypsiboas faber (7858), Leptodactylus fuscus (7859), Leptodactylus labyrinthicus (7904), Leptodactylus mystaceus (7860), Leptodactylus mystacinus (7901), Odontophrynus americanus (7863), Phyllomedusa tetraploidea (7891), Physalaemus centralis (7876), Physalaemus cuvieri (7886), Physalaemus marmoratus (7867), Rhinella ornata (7861), Scinax berthae (7911), Scinax fuscomarginatus (7910), Scinax fuscovarius (7915), Scinax similis (7883), Scinax squalirostris (7909). 